\title{
Developing a Comprehensive Taxi Strategy for Dubai: Based on System Analysis \& Structured Assessment
}

\author{
Abdulla Al Ali*, Khaled Abbas*, Mohammad Mazin* \\ Public Transport Agency, Roads \& Transport Authority, Dubai, UAE \\ Email: Abdullah.Alali@rta.ae, Khaled.Abbas@rta.ae,Mohammad.Mohammad@rta.ae
}

How to cite this paper: Al Ali, A., Abbas, K. and Mazin, M. (2017) Developing a Comprehensive Taxi Strategy for Dubai: Based on System Analysis \& Structured Assessment. Journal of Transportation Technologies, 7, 261-278.

https://doi.org/10.4236/jtts.2017.73018

Received: March 6, 2017

Accepted: May 29, 2017

Published: June 1, 2017

Copyright (c) 2017 by authors and Scientific Research Publishing Inc. This work is licensed under the Creative Commons Attribution-NonCommercial International License (CC BY-NC 4.0).

http://creativecommons.org/licenses/by-nc/4.0/

\begin{abstract}
Taxi plays an important role in providing passenger mobility. Taxi services are among the most frequently used passenger transport services in many cities in the world. Taxis are an integral part of a city's image. In a recent IRU/EU report taxis are considered as part of the collective public transport chain. In this context taxis role is a complementary mobility option to public transport rather than a competitive one. In the growing city of Dubai taxis are utilized by many local and foreign residences as well as by tourists and visitors. The annual number of taxi trips reached 104 million trips in 2016, while the fleet is growing currently at 9613 and is expected to reach around 12,765 by 2020. Riding a taxi in Dubai is known to be pleasant, comfortable, convenient and relatively affordable experience. The Roads and Transport Authority (RTA) is the Dubai government authority responsible for the planning and governance of the taxi sector in Dubai. The RTA through its agency namely the Public Transport Agency (PTA) exercises such roles. This research is meant to provide a system analysis and structured assessment of the taxi sector in Dubai with the objective of identifying strengths and gaps as well as reviewing the literature and conducting stakeholder consultation hence culminating on developing a comprehensive taxi strategy in Dubai. Such strategy would be targeted to achieve customer satisfaction leading eventually to customer happiness. All in all this is expected to provide an added value and benefit to the business planning for PTA as well as for the overall strategic and futuristic planning by RTA.
\end{abstract}

\section{Keywords}

Taxi, Strategy, System, Analysis, Structured, Assessment, Dubai 


\section{Introduction}

Taxi services are among the most frequently used passenger transport services in many cities in the world. A review of literature issued by several countries and international organizations indicated that taxi service is not regarded as a competitor to mass transit systems but on the contrary can be considered as a supplement to assist in achieving an integrated mass transit system. A quotation from the cover page of a recent IRU report has iterated the statement, see [1] "Taxis Are Part of the Collective Public Transport Chain". Also it is vital to note that the policies and measures developed to minimize the use of cars often lead to a shift of car users from cars to taxis. This falls in line with what is reported by Singapore Land Transport Authority, see [2] "While Public Transport Is the Most Efficient Means of Travel, Taxis Bridge the Gap between Commuting and Driving a Car". Taxis can be also considered as one of the main Mobility Management Options as taxi occupancy in many cities averages between 1.5 to 2 passengers excluding drivers which assist in achieving the mobility notion of reducing Single Occupancy Vehicles (SOV) and increasing High Occupancy Vehicles (HOV). Adapted from [3] "Taxis fill a gap in public transport provision, providing services in places and at times when other forms of public transport are unavailable, and for those who are unable to access buses, the metro due to disability or mobility impairment. Taxis are used by both the highest earning in the society and those on lower incomes, for business and leisure purposes, at every hour of the day and night".

The Taxi sector in Dubai is experiencing substantial changes and challenges. Powerful market and economic forces are affecting the objectives, roles, size and structure of this sector. A taxi strategy is meant to understand where we want the taxi system in Dubai to be in the future and how this can be achieved. Such strategy spells out the future direction for the taxi system in Dubai, with a clear set of goals, objectives, policies and initiatives. In this context, this research starts by developing a conceptualisation of taxi system components \& stakeholders in Dubai. This is followed by classification of core activities, components and enablers of taxi sector in Dubai.

The purpose of this research is to provide a system analysis and structured assessment of the taxi sector in Dubai. A semantic assessment; using 30 factors, is conducted. Based on these assessments and diagnostic identification of gaps, issues and potential improvement opportunities, this research develops a comprehensive taxi strategy for Dubai. Such strategy involves deciding on acceptable values, vision, mission statement and strategic goals for the taxi sector in Dubai. This will culminate, based on the authors' analysis, several other sources and literature review, into compiling a continuum of $100+$ policies, measures and initiatives that can be followed to attain the preset strategic goals. These are classified under 12 main headings namely: Taxi Depots \& Taxi Ranks, and Infrastructure, Taxi Fleet and supporting facilities/services ITS research innovation and development, Taxi Services, Fare Policy \& Structure, Marketing, Branding \& Image, Planning \& service design, Procurement/Decommissioning, Operation \& 
Maintenance, Legislation Monitoring \& Governance, Quality Health Safety \& Environment, Human Resources (Drivers \& Inspectors) \& Working Environment.

\section{Methodology}

The following presents the 6 steps methodology followed in this research:

1) Develop a conceptualisation of taxi system components \& stakeholders in Dubai.

2) Develop a classification of core activities, components and enablers of taxi sector in Dubai.

3) Conduct a description of the characteristics and KPIs of taxi system in Dubai.

4) Conduct a multicriteria semantic assessment of the taxi sector in Dubai. This is meant to assist in identifying strengths and gaps as related to the taxi sector in Dubai.

5) Conduct an international bench-markings review of taxi provision in Dubai as compared to other cities.

6) Develop comprehensive taxi strategy for Dubai taking into consideration to overcome gaps and improve overall taxi system in Dubai. Such strategy has its focus on achieving customer happiness.

\section{Conceptualisatıon of Taxi System Components \& Stakeholders}

This paper develops in Figure 1 a generic conceptualisation of system compo-

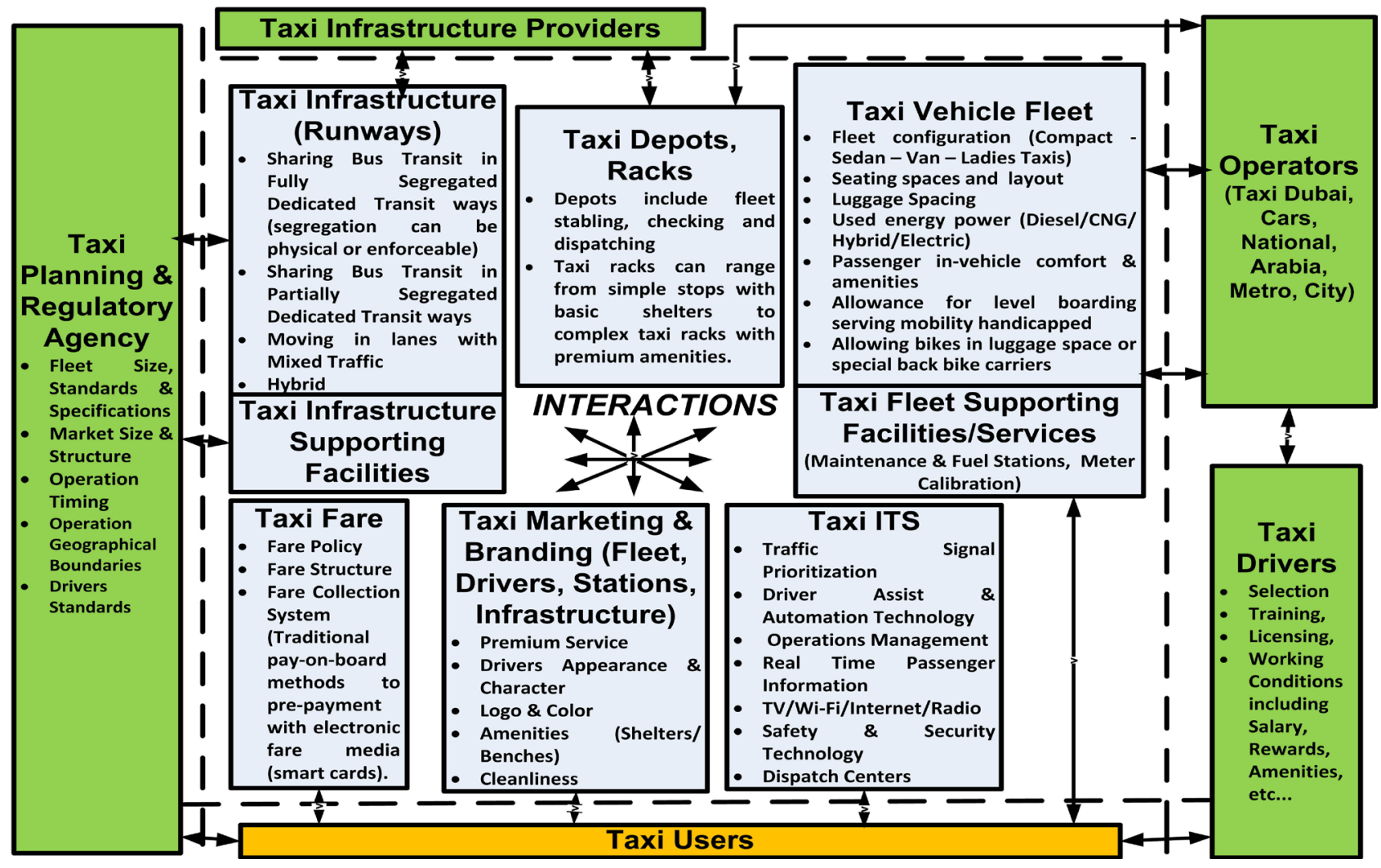

Figure 1. Taxi system components \& stakeholders, source: adapted from [4]. 
nents \& stakeholders that is typical of many taxi sectors in world cities including Dubai. Eight components \& five stakeholders were identified as constituting taxi system in Dubai as follows:

\section{Components}

1) Taxi Infrastructure (Runways) - These could range from

- Moving in lanes with Mixed Traffic

- Sharing Bus Transit in Partially Segregated Dedicated Transit ways

- Sharing Bus Transit in Fully Segregated Dedicated Transit ways (segregation is physical or enforceable)

- Hybrid

2) Taxi Depots and Taxi Ranks where depots are used for fleet stabling, checking and dispatching taxis. As for taxi ranks these can range from simple stops with basic shelters to complex taxi ranks with premium amenities. In developing taxi ranks several design parameters should be taken into account including safe and operationally friendly layout considering stopping lay bays, overtaking lanes, access and egress, etc.

3) Taxi Vehicle Fleet including aspects such as:

- Fleet configuration (Compact - Sedan - Van - Ladies Taxis)

- Seating spaces and layout

- Luggage Spacing

- Used energy power (Diesel/CNG/Hybrid/Electric)

- Passenger in-vehicle comfort and amenities

- Allowance for level boarding serving mobility handicapped and other passengers

- Allowing bikes on board in luggage space or special back bike carriers

4) Taxi Infrastructure Supporting Facilities such as signs and markings

5) Taxi Fleet Supporting Facilities, Units \& Services including fleet maintenance, fueling facilities, meter calibration facilities

6) Taxi Fare including determination of Fare Policy and Structure as well as Fare Collection System (varying from traditional cash pay-on-board methods to cashless payments using bank card payment as well as pre-paid payment with electronic fare media e.g. smart NOL cards).

7) Taxi Marketing/Branding/Imaging of Fleet/Drivers/Stations/Infrastructure including:

- Premium Service

- Driver Appearance, Behaviour and Character

- In and out vehicle appearance, logo \& colour-In and out vehicle cleanliness

- Vehicle amenities (Wi-Fi-Phone Charging Sockets, News Reporting, TV Radio)

- Stations, stops, shelters, benches

8) Taxi ITS

- Traffic Signal Prioritization

- Driver Assist and Monitoring Technology

- Operations Management Technology 
- Real Time Passenger Information

- Safety \& Security Technology

- Taxi Dispatch centers

\section{Taxi Stakeholders}

1) Taxi Planning \& Regulatory Agency. This is currently represented in Dubai by Public Transport Agency (PTA) responsible for planning and regulating fleet size, standards \& specifications, market size \& structure, operation timing, operation geographical boundaries, driver's standards etc.

2) Taxi Infrastructure Providers by Traffic and Roads Agency (TRA) within RTA.

3) Taxi Operators-Currently in Dubai includes 6 taxi companies-one semi government known as Dubai Taxi and the other 5 are private including Arabia-Car-City-Madina-Metro.

4) Taxi Drivers-This is handled in Dubai by the Drivers affairs Department within PTA who is responsible for Drivers' Selection, Training and Licensing, while on the other hand the taxi companies are responsible for drivers' working conditions including salary, rewards, amenities, etc.

5) Taxi Users/Customers.

\section{Classification of Core Activities, Components \& Enablers of Taxi Sector in Dubai}

Building on the above conceptualization of taxi system components, Figure 2 shows a further classification of core activities, components and enablers typical

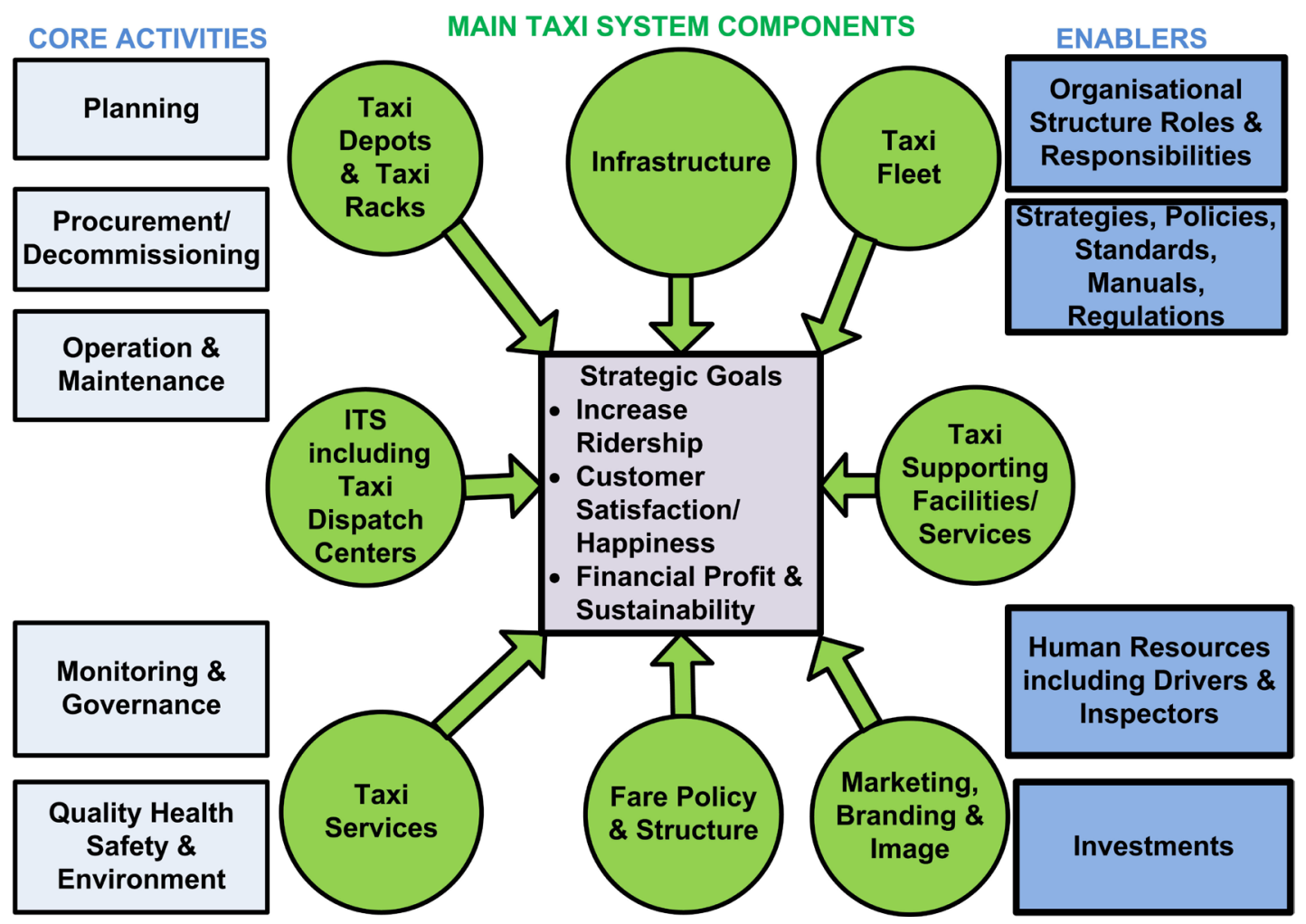

Figure 2. A classification of core activities, components \& enablers of taxi sector in Dubai. 
of many taxi sectors in the world including Dubai. These can be classified as follows:

Core Activities (planning \& services design - procurement \& decommissioning - operation \& maintenance monitoring \& governance - quality health safety security and environment).

Components (infrastructure - depots and taxi ranks - fleet - supporting facilities - ITS \& dispatch centers - taxi services, fare policy and structure, marketing, branding and imaging).

Enablers (organisational structure \& roles and responsibilities - strategies, policies, standards, manuals, regulations - human resources \& work environment - investments).

The figure also shows that at the center of all of these core activities, components and enablers are the strategic goals of increasing ridership, customer satisfaction/happiness and financial profitability and sustainability.

\section{Taxi System in Dubai: Main Characteristics and KPIs}

In this section, a number of characteristics that describes the taxi system in Du-

bai are reported in Table 1 . These characteristics cover the main taxi system

Table 1. Characteristics of taxi system in Dubai, source: compiled from [5].

\begin{tabular}{|c|c|}
\hline CHARACTERISTICS OF TAXI SYSTEM IN DUBAI & DESCRIPTIONIREPORTING \\
\hline Fleet Size & 9613 taxis \\
\hline Dubai Population & 2,590,718 capita \\
\hline Fleet per 1000 Population & 3.71 taxis per 1000 population \\
\hline Service Types & $\begin{array}{c}\text { Street Hail Taxis - Airport Taxis - Hala Taxis via Booking - Ladies Taxis - Special } \\
\text { Needs Taxis - Premium Taxis }\end{array}$ \\
\hline Fleet Types & Toyota - Nissan - Hyundai - Chevrolet \\
\hline Taxi Operators & 6 Companies (Dubai Taxi-Arabia-Car-City-Madina-Metro) \\
\hline Daily Trips & 244,938 trips/day \\
\hline Daily Trips Per Taxi & 25 trips/taxi/day \\
\hline Daily Kilometers & $4,838,660 \mathrm{~km} /$ day \\
\hline Daily Kilometers per Taxi & $503 \mathrm{~km} /$ taxi/day \\
\hline Daily Revenue Kilometers & $2,409,914 \mathrm{~km} /$ day \\
\hline Daily Revenue Kilometers per taxi & $251 \mathrm{~km} /$ taxi/day \\
\hline Average roaming trip distance & $10 \mathrm{~km}$ \\
\hline Average Revenue Trip Distance & $10 \mathrm{~km}$ \\
\hline Revenue kilometers to total kilometres & $50 \%$ \\
\hline License Plate Franchise Duration & 3 years \\
\hline Average Taxi Trip Occupancy & $1.74 /$ taxi/trip \\
\hline Payment Options & Cash - Cashless via Bank Cards - Pre-paid via NOL Cards \\
\hline Taxi Fare Structure & See Figure 3 (Official Taxi Dashboard Passenger Fare Information) \\
\hline
\end{tabular}




\section{Minimum Fare AED 12}

Free journey if the meter is not operated

الرحلة مجانية إذا لمم يُشغَل العداد

AED 20 added while passing Sharjah يضاف 20 درهماً عند المرور بإمارة الشارقة

When passing through Salik gates, toll gate charges will be billed to the customer. For alternative Salik free routes, kindly inform driver at the start of your trip.

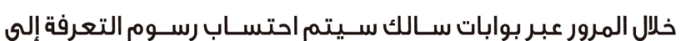

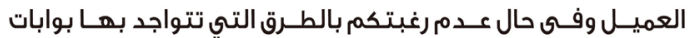

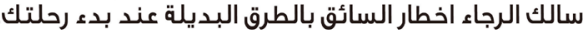

\begin{tabular}{|c|c|c|c|c|c|c|c|c|c|c|c|c|c|}
\hline \multirow{3}{*}{$\begin{array}{r}\text { Service Type } \\
\text { After Increase }\end{array}$} & \multicolumn{3}{|c|}{ 6:00 Am - 10:00 Pm } & \multicolumn{3}{|c|}{ 10:00 Pm - 6:00 Am } & \multicolumn{3}{|c|}{ 10:00 مساء - 6:00 صباحا } & \multicolumn{3}{|c|}{ 6:00 صباحاً - 10:00 مسائ } & \multirow{2}{*}{ نوع الزيادة } \\
\hline & \multicolumn{2}{|c|}{ Meter } & \multirow{2}{*}{\begin{tabular}{|c|}
$\begin{array}{c}\text { 07:00Am - } \\
\text { 10:00Am }\end{array}$ \\
$\begin{array}{c}\text { Peak } \\
\text { Hour }\end{array}$ \\
\end{tabular}} & \multicolumn{2}{|c|}{ Meter } & \multirow{2}{*}{$\begin{array}{l}16: 00 \mathrm{Pm} \text { - } \\
\text { 20:00Pm } \\
\text { Peak Hour }\end{array}$} & | 16:00 مساء: & \multicolumn{2}{|c|}{ فتح العداد } & | l & \multicolumn{2}{|c|}{ فتح العداد } & \\
\hline & $\begin{array}{l}\text { Road } \\
\text { Pickup }\end{array}$ & Dispatch & & $\begin{array}{c}\text { Road } \\
\text { Pickup }\end{array}$ & Dispatch & & الذاعرة & 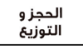 & الرحنة المباشرة & الذاعرة & التوزيغ & | الرحنة المباشرة & \\
\hline Public Taxi & AED 5.00 & AED 8.00 & AED 12.00 & AED 5.50 & AED 9.00 & AED 12.00 & ل 12.00 درهمم & 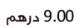 & ل - 5.50 درهم: & 12.00 درهمم & 8.00 درهم & (5.00 درهم & التاكسي العادي \\
\hline Special Needs Taxi & AED 25.00 & AED 8.00 & AED 12.00 & & AED 9.00 & AED 12.00 & 12.00 درهمم & 9.00 درهمم & & | & | 8.00 درهم & 25.00 درهمم & ذوي الاتياجساقِ الفاصة \\
\hline Ladies \& Families Taxi & AED 8.00 & AED 8.00 & AED 12.00 & AED 9.00 & AED 9.00 & AED 12.00 & 12.00 درهمم & 9.00 درهمم & 9.00 درهم & 12.00 درهمم & 8.00 درهم & 8.00 درهم & تاكسي السيدات والعائلات \\
\hline Hala Taxi & & AED 8.00 & & & AED 9.00 & AED 12.00 & 12.00 درهمم & (9.00 درهمم & & & 8.00 درهمر & & هلا تاكسي \\
\hline \multicolumn{7}{|c|}{$\begin{array}{l}\text { Fare of booking a vehicle for } 6 \text { hours AED } 500 \\
\text { and for } 12 \text { hours AED } 800 \text { (within Dubai only) }\end{array}$} & \multicolumn{7}{|c|}{ درهم ولـ 12 ساعة حجز المركبـة لـ 600 ساعات 800 درهم (في دبي فقط) } \\
\hline \multicolumn{7}{|c|}{ For complaints and suggestions: للشكاوي والإقتراحات: 909000} & \multicolumn{7}{|c|}{ To book: 042080808 للحجز } \\
\hline \multicolumn{3}{|c|}{ ع اصطحاب الحيوانات } & \multicolumn{3}{|c|}{ ممنوع التدخين } & \multicolumn{2}{|c|}{ ممنوع الأكل والشرب } & \multicolumn{3}{|c|}{ استخدم حزام الأمان } & \multicolumn{3}{|c|}{ لاتنس أمتعتك الشخصية } \\
\hline
\end{tabular}

Figure 3. In vehicle taxi sticker showing taxi fare structure, source: see [5].

components showing that the fleet size in Dubai is 9613 taxis with a taxi availability ratio of 3.71 per 1000 population. Additionally the table shows the different offered service types including ladies taxis which are one of the first in the world taking into consideration gender specific requirements as well as taxi on demand labelled Hala. Taxis in Dubai are operated via 6 companies. An interesting indicator shown in Table 1 is that taxis in Dubai roam half of their operation time and the other half they have riding customers. Taxis travel daily almost $500 \mathrm{~km} 250$ vacant and 250 with passengers. License franchise duration is 3 years and recently extended to 5 years and average occupancy is around 1.74 passengers per taxi trip. There are several methods to pay taxi fare some are part of the integrated public transport fare policy in Dubai known as NOL. The fare starts by 5 AED (1.4 USD) with a minimum journey fare of 12 AED (3.3 USD).

Additionally, a KPI assessment was conducted based on the latest data available in [6], see Table 2.

\section{A Multicriteria Semantic Assessment of the Taxi Sector in Dubai}

A multicriteria semantic assessment of taxi sector in Dubai is conducted. Such assessment is meant to assist in identifying strengths and gaps in performance. This is reported in Table 3. 
Table 2. KPI assessment of taxi sector in Dubai, source: see [6].

\begin{tabular}{ccc}
\hline KPI & TARGET & ACTUAL \\
\hline Accidents/100,000 Km & 0.25 & Not Reported \\
Quality Violations/100,000 Km & 0.75 & 0.8 \\
Valid Complaints/100,000 Km & 1.35 & 0.81 \\
Refusal to transport passengers/1,000,000 & 0.3 & 0.13 \\
Refused to Stop/1,000,000 & 0.1 & 0.03 \\
Bad Staff Conduct/1,000,000 & 0.3 & 0.54 \\
Reckless Driving/1,000,000 & 0.25 & $82 \%$ \\
Customer satisfaction & $90 \%$ & $79 \%$ \\
Peak Vehicle Operation & $87 \%$ \\
\hline
\end{tabular}

Table 3. Semantic multi-criteria assessment of taxi sector in Dubai.

\begin{tabular}{|c|c|}
\hline ASSESSMENT CRITERIA & SEMANTIC ASSESSMENT OF TAXI SECTOR IN DUBAI \\
\hline Ownership & $\begin{array}{l}6 \text { companies } 1 \text { semi-public (Taxi Dubai owned by RTA) \& } 5 \text { private - Taxi Dubai is dominating the } \\
\text { market with a market share in terms of fleet size around } 45 \%\end{array}$ \\
\hline Market Size & $\begin{array}{l}\text { A Taxi Requirement } 5 \text { Year Plan 2016-2020 was Endorsed allowing the taxi fleet to reach 12,765 by } 2020 \\
\text { - } 6 \text { Companies are allowed to operate including Dubai Taxi-Arabia-Car-City-Madina-Metro-Market } \\
\text { size has the potential to grow-however market size is regulated by PTA }\end{array}$ \\
\hline Market Entry/Exit & $\begin{array}{l}\text { Regulated by RTA (Only } 6 \text { Companies are currently allowed to provide taxi services)-Market exit rules } \\
\text { should be developed }\end{array}$ \\
\hline Fare Determination & $\begin{array}{l}\text { Decided by planner/regulator to insure a balance between taxi companies profitability and customer } \\
\text { satisfaction }\end{array}$ \\
\hline Regulation & Exercised by PTA which is an RTA government agency. This presents a partial conflict of interest \\
\hline Regulatory Regime & $\begin{array}{l}\text { Moderate (Encouraging rather than discouraging and maintaining a balance between companies } \\
\text { financial sustainability and customer satisfaction/happiness) }\end{array}$ \\
\hline Regulatory Aspects & $\begin{array}{l}\text { Market Size - Entry to market - Quality and Age of Vehicles - KPIs including safety customer } \\
\text { satisfaction, driver and operation standards, etc. }\end{array}$ \\
\hline Market Competition/ Monopoly & $\begin{array}{l}\text { Yes (intermodal between the } 6 \text { taxi companies and modal between taxi sector and other modes such as } \\
\text { Limo, bus, metro, car, etc.) However taxi Dubai has a share of } 45 \% \text { of the taxi fleet while other } \\
\text { companies range from } 0.4 \% \text { for city taxi to } 17 \% \text { for Cars showing a market imbalance with Dubai taxi } \\
\text { almost creating a semi monopoly. There is a potential for small taxi companies to merge to create a } \\
\text { more balanced competitive market. }\end{array}$ \\
\hline Government Involvement & Yes \\
\hline Attractiveness of Market Entry & Very High \\
\hline Strategic Planning & Yes by PTA/RTA \\
\hline Goals & Main goals are Financial Viability, Sustainability \& Customer Satisfaction/Happiness \\
\hline Funding & Mixed (Government \& Private) \\
\hline Pricing Policy & Determined by Regulator (PTA) \\
\hline Subsidy & Limited (Some Social Services such as special needs services) \\
\hline Organizational Structure & Developing \\
\hline Management/Decision Powers & High \\
\hline Legal Structure & Developing \\
\hline
\end{tabular}




\section{Continued}

Accountability High

High Quality Human Resource

Management \& Capacity Building

Technology \& Innovation

Many applications are in place

Research \& Development

Limited

Service Quality

High

Call Services

Hailing - Booking and Taxi Ranks

Operational Efficiency

High

Financial Efficiency \& Cost Control

Staff Productivity

High

High

Asset Utilization

High

Safety Concerns

Low

\section{International Benchmarking: Taxi Availability Index}

Many world cities report a taxi indicator as the average number of taxis per 1000 population. According to [7] this indicator is labelled as the Taxi Availability Index (TAI). The average availability index across 23 cities in the world is equal or higher than 3 taxis per 1000 population, see Figure 4 for a comparison between these cities. It is obvious that some cities such as Dubai, London, Barcelona, Prague, Stockholm, Dublin and Washington are above this average, while on the other hand Melbourne, Vancouver, Brussels and Sydney are below such average. It is also worth mentioning that growing Asian cities like Singapore has a high taxi-to-population ratio of 5.2 taxis per 1000 persons, while Dubai is currently at 3.71 taxis per 1000 population and targeting to achieve taxi availability index of 4.09 taxis per 1000 population in the coming few years.

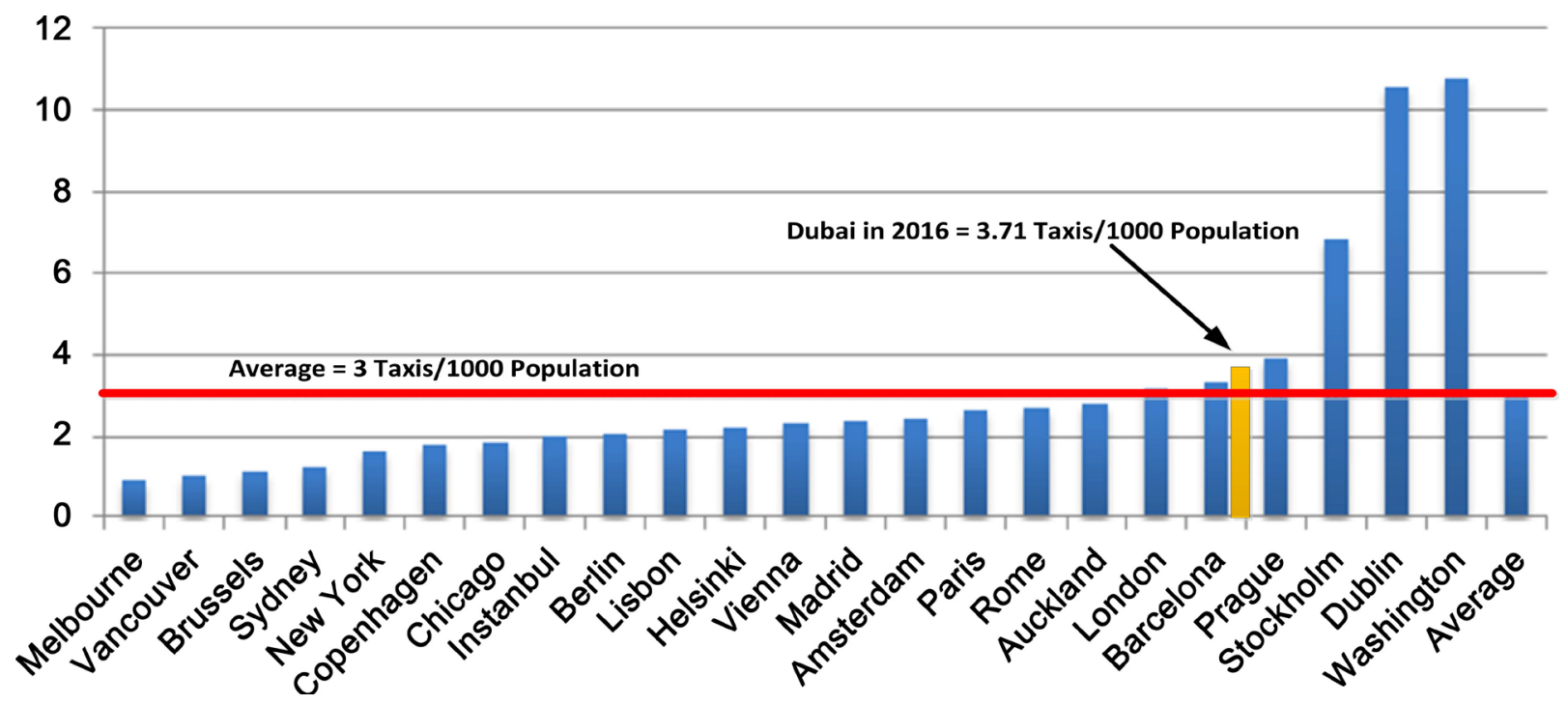

Figure 4. Comparison of taxi supply among selected European cities, source see [8]. 


\section{Developing a Taxı Strategy for Dubai}

Developing and implementing a well thought strategy for the taxi sector in $\mathrm{Du}$ bai is detrimental to achieving the main strategic goals of customer happiness, financial sustainability and mobility provision. Towards this end a comprehensive taxi strategy for Dubai is shaped taking into consideration to overcome gaps and step into the future with achieving customer happiness. The following generic steps are involved in preparing such a strategy:

- Identifying changes affecting the taxi sector in Dubai

- Deciding on acceptable values for the Taxi sector in Dubai

- Determining the vision and mission statement for the Taxi Sector in Dubai

- Determining the strategic goals for the Taxi Sector in Dubai

- Identifying a continuum of necessary policies, measures and initiatives that can be followed to attain the preset strategic goals. These are classified covering the core activities, components \& enablers of taxi sector in Dubai depicted in Figure 2.

\subsection{Changes Affecting the Taxi Sector in Dubai}

A starting point is to identify the main changes that should be taken into account in shaping and formulation of values, vision, mission statement, strategic goals as well as the proposed policies, measures and initiatives of the Taxi sector in Dubai. These include:

- Customer happiness including taxi customers being at the core focus in Dubai.

- Geographical spread and increase of developments in Dubai, this entails more mobility demands.

- Smart booking companies such as Uber and Careem strongly penetrating the mobility market.

- Safety and security issues high on the agenda due to occurrences of accidents that attracted public and mass media attention.

- Rapid world-wide development in the areas of communications and information technology.

- Concerns on environment and sustainability issues.

- Innovative changes taking place in taxi industry such as smart booking, dynamic information, electronic payment systems.

- Increasing role of private sector multinationals.

- Reduction in potential and size of private capital flows.

\subsection{Proposed Values, Vision and Mission Statement for Taxi Sector in Dubai}

The following set of values are identified and proposed as a suitable framework governing the work of the taxi sector in Dubai:

\begin{tabular}{ccc}
\hline Customer Focus & Professionalism & Teamwork \\
Excellence & Fairness & Transparency \\
Innovation & Perfectionism & Responsiveness \\
\hline
\end{tabular}


The vision for the taxi sector in Dubai can be contemplated as follows: "Achieving one of the safest, green, best performing, reliable, customer-focused and sustainable taxi systems in the world that offer commercially viable, high quality and value for money services".

The mission statement for taxi sector in Dubai can be also proposed and stated as follows: "Complementing the mobility options in Dubai by ensuring adequate provision (at the right place and the right time with the right price and the right quality) management, operation and maintenance of various taxi services to meet and exceed expected taxi demand with levels of service instigating customer satisfaction and further customer happiness. This should be done in an integrated, efficient, safe and secure manner taking into consideration minimising disruption to the environment and saving energy, hence attaining a sustainable taxi system that is customer focused."

\subsection{Proposed Strategic Goals for Taxi Sector in Dubai}

A number of strategic goals are identified and proposed for the taxi sector in Dubai. These include:

- Ensuring provision of taxi services required to meet and exceed expected demand levels in terms of quantity and quality - targeting achieving customer satisfaction and eventually customer happiness.

- Ensuring provision of taxi infrastructure and services is oriented towards achieving sustainability goals i.e. achieving a balance between economic, environmental and social dimensions covering aspects of financial efficiency, environment protection, safety, energy efficiency.

- Stimulating more private sector involvement and participation.

- Ensuring a balance between taxi companies' profitability and taxi users' satisfaction/happiness.

- Ensuring high quality of human resource management, training and capacity building.

- Ensuring introduction of innovatory technologies and methods in the taxi sector.

- Increasing the financial efficiency of operation, maintenance and management of all taxi infrastructure and services through profit maximization and cost minimization.

- Ensuring taxi services are affordable, reliable, responsive, safe and pleasant.

\subsection{Proposed Policies, Measures \& Initiatives for Taxi Sector in Dubai}

The next step in the preparation of a strategic plan is to propose and compile the policies, measures \& initiatives for the taxi sector in Dubai. In addition to authors' analysis and insights, this is based on suggestions obtained from several RTA official teams and stakeholders and literature review including:

- Taxi Customer Happiness Team

- Taxi Customers Forum 
- Committee for Business Enhancement of Public Transport Agency

- Customer Service Team

- Tomorrow Team

- Consultations with 6 Taxi companies operating in Dubai

- Comprehensive literature review conducted sourcing the following [3] [9]-[18].

Based on the above the following presents a number of policies, measures and initiatives that are proposed for taxi sector in Dubai. These are classified under 12 main headings.

1) Taxi Infrastructure - Depots \& Taxi Ranks

- Redesign the taxi related information signs across Dubai to be more legible and in several languages.

- Increase the number of taxis ranks in public and entrainment areas in Dubai. Also at major public transport stations (metro and bus) to allow for better transport integration. Providing taxi ranks has a number of benefits relating to safety and availability, as well as potentially reducing congestion and vehicle emissions as drivers are not forced to continually drive around to look for work.

- Continue to conduct a comprehensive review of all ranks to identify improvements and where new ranks are needed.

2) Taxi Fleet \& Supporting Facilities/Services

- Update customer rights stickers inside taxis.

- Equip vehicles with foldable child car seats and restraints.

- Ensure that taxi fleet is cleaned from outside and inside on a daily basis and that inside cleaning includes smell removal and air fresheners. This should be also regulated.

- Improve maintenance of existing taxi fleet and introducing state of the art taxi fleet management systems.

- Equip some of the taxi fleet with sufficient space to carry bicycles.

- Unify taxi plate and vehicle appearance among the 6 companies in Dubai.

- Recommend to taxi companies to develop taxi fleet manuals to demonstrate the in and out vehicle components their usage as well as to demonstrate the maintenance process for taxi vehicles.

- Consider introducing a specially designed uniform look for Dubai taxis that is sleek, functional, aesthetically appropriate, accessible for all, clean-air fueled, durable and user-friendly.

- Consider the introduction of a separate passenger compartment with a full partition to provide a greater degree of safety and privacy.

- Provide Shaded and air conditioned waiting areas for taxis especially at airport.

3) ITS Research Innovation \& Development

- Dispatch center to be modernized with updated equipment, booking software and road maps.

- Ensure that current PTA taxi dispatch center is expanded \& consider the 
possibility of each taxi company to have its own dispatch center.

- Ensure that all taxis are equipped with external screens showing vacant - occupied - out of service.

- Providing interactive in vehicle screens for taxis in airports.

- Include a barcode within interactive screens to provide tourist information for visitors.

- Add a feature to interactive screens to allow passengers to complete customer satisfaction questionnaires.

- Consider automatically stopping the taxi in case the taxi meter is disconnected.

- Develop state of the art booking applications such as Dubai Integrated Mobility Platform (DIMP).

- Ensure SMS service is provided to alert customers with different milestones in their taxi journeys.

- Looking at state of the art technologies in transport field and adapt, not adopt the most suitable of these to introduce more efficiency improvements into the operation and maintenance of taxi sector in Dubai.

- Develop in vehicle driver monitoring system for alert reward and violation identification, see [11].

- All metered taxi should have a Global Positioning System (GPS).

\section{4) Taxi Services}

- Provide more in vehicle amenities such as interactive screens, mobile telephone charging, Wi-Fi.

- Taxis to be linked to Personal Location Identification Application.

- Adding an application to allow customers to have more than one registered address.

- Ensure the provision of tourist/visitor information/leaflets/booklets/maps /brochures.

- Consider launching a special taxi service for tourists and visitors

- Ensure that taxi service is part of travelers and visitors airline and hotel packages.

- More market segmentation with designing special services for families, business travelers, mobility impaired including visually impaired, wheel chairs, ear impairment, old people, children, women in maternity etc.

- Provide local transit service using shared taxis.

- Replacing Low-Demand Bus Routes with Taxis.

5) Fare Policy \& Structure

- Consider an updated fare structure and policy that considers fare variation with congested times and different levels of services.

- Ensure that customers pay a percentage in case of cancelling their bookings.

- Recommend and encourage taxi companies to develop business plans and road map.

- Introduce joint taxi-transit pay mode such as NOL.

\section{6) Marketing, Branding \& Image}


- Develop and implement an education campaign for the general public to enhance respect for front-line taxi workers.

- Prepare a promotional branding and image plan including drivers and their role in providing the service.

- Launch promotional campaigns with the beginning of the school year to promote taxi services for school and university students.

- Launch a promotional campaign to encourage the use of taxis for several chained trips.

- Launch marketing campaigns with Banks and Brand Shops customers offering good value for money discounts and promotional packages for companies, associations, government enterprises and individuals.

\section{7) Planning \& Service Design}

- Adopting the notion of intermodality and plan for the integration of taxi services with other public and private modes so as to maximize the efficiency of utilization.

- Consider new franchise business models for taxi companies including possible changes in contract duration, monthly fees, license plate, etc.

- Establishing processes for effective participation of taxi users in making decisions on the planning and management of the taxi sector in Dubai.

- Developing continuous education, mass media and information campaigns to set the right scene for public acceptability and support for the taxi sector in Dubai.

- Developing a comprehensive and continuous data collection programs covering all aspects of the taxi system - thus developing a data base and Information Management System leading to a Decision Support System.

\section{8) Procurement/Decommissioning}

- Continue to grow the taxi fleet in Dubai to achieve and sustain the target taxi availability index of 4.09 taxis/1000 capita.

- Contemplate to remove/loosen taxi supply restrictions as an increasing number of countries have removed or loosened supply restrictions on taxis-this resulted in reduced waiting times, increased customer satisfaction and falling taxi prices being observed.

\section{9) Operation \& Maintenance}

- Taxi Fleet to be provided with updated road and buildings address maps \& drivers to be trained on how to use such mapping system.

- Taxi Meters to be linked to bank card payment network to allow cashless payments by customers using bank cards or prepaid NOL cards.

- Drivers' shift change periods to be staggered with peak traffic periods.

- Reconsider the drivers' incentive policy that relies on number of trips as it discourages drivers from accepting long journeys (incentives to be related to revenue-kilometers rather than to number of trips).

\section{0) Legislation Monitoring \& Governance (Enforcement)}

- Reconsider the KPI system used to monitor and regulate taxi companies.

- Ensure the appropriate regulation of smart transport booking companies 
known as e-hail companies (such as Uber, Careem etc.).

- Warning visitors at Dubai ports of not using non-licensed taxi services.

- Ensure continuity in carrying out planned and random inspection campaigns on drivers.

- Reviewing and updating legislation, laws and regulations pertaining to taxi sector in Dubai.

- Provide legislation necessary to facilitate and promote the implementation of new service and changes in existing services.

- Develop state of the art technology based regulatory regime such as the Regulatory Management System (RMS) planned to be in place in Dubai.

- Ensure that regulations are updated to cater for children as taxi passengers.

- Review market entry requirements to ensure more competitive market and avoid any form of full or partial monopoly.

- A better resourced and trained inspectorate is needed to enforce both the licensing system and the envisaged regulations.

\section{1) Quality Health Safety \& Environment}

- Taxi fleet to be equipped with speed control devices and driver warning system in case speed limit is exceeded - taxi drivers' violators to be automatically identified and penalised.

- Taxi vehicle periodical inspection to be every 6 months rather than every year.

- Ensure holding a prestigious annual competition to award best taxi company.

- Ensure that lost and found system is easy to communicate with and recover.

- Launch a taxi rider loyalty program with points and rewards.

- Introduce a new environmentally friendly service labeled Eco Taxi \& ensure that at least $50 \%$ of new fleet is environmentally friendly (Hybrid or Fully Electrical).

- Consider drivers suggestions seriously and reward and encourage such suggestions.

- Accident reporting system to be developed that is characterized by speed and accuracy in reporting.

- Manage driver fatigue with work planning.

- Conduct mass media campaigns to inform customers of their rights and duties when utilizing the taxi system.

- Conduct a study to understand and identify the areas and the type of drivers and customers who are involved in passenger smuggling.

- Introduce more internationally used KPIs for benchmarking and quality regulation including average wait time to get a taxi, average wait time on the phone for taxi booking, fatalities per 100,000 kilometers.

- Develop an efficient and smart in vehicle customer satisfaction/happiness questionnaire.

- Introduce a requirement for taxi drivers to display photographic identification with name and contact details in all taxi rides.

- Enhance fatigue management requirements for all taxi drivers. 


\section{2) Human Resources (Drivers \& Inspectors) \& Working Environment}

- Introduce an end shift application to avoid sending bookings to drivers after their shift ending.

- Add out of shift feature to ensure that drivers rest time is respected and adhered to.

- Double the number of drivers to be acknowledged and rewarded from 50 to 100 drivers and increase the number of reward cycles per year (quarterly or bi annually rather than annually).

- Ensure the provision of in vehicle camera to monitor the driver behaviour and avoid having these cameras directed to passengers as this encroaches on passengers privacy.

- Ensure the unification of drivers selection, induction, training and licensing procedures across the 6 taxi companies.

- Ensure that all drivers trainers are consistently trained to provide a homogenous drivers training programs-trainers and examiners can be drawn directly from the ranks of licensed Dubai taxi drivers themselves.

- Ensure the update of the drivers training material to be in accordance with best practice standards and ensure that drivers are not licensed except after passing all licensing qualifications steps.

- Ensure that resigning drivers are interviewed by customer service team.

- Ensure launching mass media campaigns to promote status of taxi drivers in society.

- Ensure rewarding inspectors on revenue generated from correct fines.

- Ensure inspectors are dressed in law enforcement dress that gives them status.

- Ensure that drivers appearance is checked \& monitored on a daily basis.

- Training of call center staff to classify complaints properly and take quick action if necessary.

- Consider extending the driving shifts to a total of 12 hours with the proper rest periods that is internationally accepted. Additionally make provision for 1 day rest per week.

- Prevent transfer of drivers between franchise companies or to/from limousine companies except after providing no objection certificate from his/her previous company.

- Periodically review incentives, penalty and retention schemes and consider more rewards for excellent drivers utilizing a percentage of the fines revenue.

- Develop a drivers handbook that include all necessary instructions, information, protocols and required behavior (code of conduct).

- Conduct drivers awareness campaigns.

- Consider providing drivers with a decent basic salary and incentives to partially complement such salary.

- Establish a standard requirement for drivers to include absence of the criminal record.

- Drivers to be trained and examined to ensure they have sufficient geographical knowledge of the city. Consider developing in the future the Knowledge of Dubai (KoD) test similar to Knowledge of London (KoL). The KoD can 
involve applicants having to memorise a number of streets and points.

- Improve drivers facilities in terms of accommodation, recreation, sport, cultural and religious facilities.

\section{Conclusions}

The taxi sector in Dubai has gone through several stages before reaching the current stage of maturity which can be characterized by market size stability, profitability of taxi companies and overall customer satisfaction. This research was meant to provide a system analysis and structured assessment of the taxi sector in Dubai with the objective of identifying strengths and gaps and hence developing a comprehensive taxi strategy in Dubai that is centred and focused on customer happiness. This is expected to provide an added value and benefit to the strategic and business planning role for PTA as well as for the overall business and futuristic planning role by RTA.

The research started by developing a conceptualisation of taxi system components \& stakeholders where 8 components were identified as well as 5 main stakeholders. Additionally a classification of core activities, components and enablers of taxi sector in Dubai was developed. The research conducted a description of the taxi sector characteristics and the KPI system in Dubai followed by multicriteria semantic assessment of the taxi sector in Dubai using 30 criterions. Additionally international benchmarking in terms of taxi provision in cities was reviewed where Dubai is currently at 3.71 taxis per 1000 population which is above the worldwide average of 3. Also Dubai is targeting an availability index of 4.09 taxis per 10,000 capita by 2020 .

Developing and implementing a well thought strategy for the Taxi Sector in Dubai is detrimental to achieving the main strategic goals of customer happiness, financial sustainability and mobility provision. The research concluded by developing a comprehensive taxi strategy for Dubai taking into consideration to overcome any gaps and to attain future aspirations of achieving customer happiness. The strategy identified changes affecting the taxi sector in Dubai, deciding on acceptable values, determining the vision, mission statement as well as the strategic goals for the Taxi Sector in Dubai. The strategy concluded by identifying a continuum of 101 recommended policies, measures \& initiatives that can be followed to attain the preset strategic goals. These are classified in accordance with the core activities, components \& enablers of taxi sector in Dubai.

\section{Acknowledgements}

The authors would like to acknowledge the support and encouragement provided by the RTA leadership HE Mr. Mattar Al Tayer as well as the contribution of all RTA committees, teams, forums and stakeholders involved in the taxi sector in Dubai.

\section{References}

[1] International Road Transport Union (IRU) (2013) Taxi AnyTime! AnyWhere! 
[2] Singapore Land Transport Authority (LTA) (2015). http://www.lta.gov.sg

[3] Transport Committee-London Assembly (TC-LA) ((2014) Future Proof Taxi and Private Hire Services in London.

[4] Abbas K.A. (2012) BRT Systems: Place \& Importance in the World. Opening Paper Session. Proceedings of TRANS IST 2012 5th Transportation Symposium and Exhibition, Istanbul, 27-30 November 2012.

[5] Public Transport Agency (2016) Roads and Transport Authority. UAE, Dubai.

[6] Public Transport Agency (2016) 2nd Quarter-2016 KPI Data-Roads and Transport Authority. UAE, Dubai.

[7] Abbas, K.A. (2016) Estimation of Taxi Fleet Size: A Generic Algorithm. SIGMA Journal of Engineering and Natural Sciences, 7, 21-29.

[8] Darbera, R. (2010) Taxicab Regulation and Urban Residents Use and Perception of Taxi Services: A Survey in Eight Cities. 12th World Conference on Transport Research, Lisbon, July 2010.

[9] Design Trust for Public Space (DTPS) \& New York City Taxi \& Limousine Commission (2007) Taxi 07: Roads Forward. New York City, USA.

[10] International Labour Organisation (ILO) (2003) Organising in the Taxi Industry: The South African Experience.

[11] London Taxis International (LTI) (2002) Fairway 95 Owner's Handbook.

[12] National Economic Development \& Labour Council (NEDLC) (2010) NEDLAC Report on the Metered Taxi Implementation Strategy. Development Chamber: Public Transport Task Team, South Africa.

[13] OECD (2007) Taxi Services: Competition and Regulation. Policy Roundtables.

[14] Taxi Industry Advisory Committee (TIAC) (2010) Queensland Taxi Strategic Plan 2010-2015-A Vision for the Future and Action Plan for the Next 5 Years. Queensland Government, Australia.

[15] Transport for London (TfL) (2015) Provisional Taxi and Private Hire Strategy 2015.

[16] TFP (2014) Drivers Handbook. http://www.tfpschemes.co.uk/media/10258/09-driver-handbook.pdf

[17] The San Francisco Planning and Urban Research Association (SPUR) (2001) Making Taxi Service Work in San Francisco. Final Report, San Francisco.

[18] Victoria Transport Policy Institute VTI (2014) Taxi Service Improvements. TDM Encyclopedia. 
Submit or recommend next manuscript to SCIRP and we will provide best service for you:

Accepting pre-submission inquiries through Email, Facebook, LinkedIn, Twitter, etc. A wide selection of journals (inclusive of 9 subjects, more than 200 journals)

Providing 24-hour high-quality service

User-friendly online submission system

Fair and swift peer-review system

Efficient typesetting and proofreading procedure

Display of the result of downloads and visits, as well as the number of cited articles Maximum dissemination of your research work

Submit your manuscript at: http://papersubmission.scirp.org/

Or contact jtts@scirp.org 